\title{
Frequency of Dyslipidemia in Ischemic Stroke Patients Presented to Tertiary Care Hospital of Lahore
}

\author{
MURTAZA JAFFAR ${ }^{1}$, ADIL RAFIQUE ${ }^{1}$, SIDRA KHALID ${ }^{2}$, SHAHID WAHEED ${ }^{3}$ \\ ${ }^{1}$ House Officer, Sheikh Zayed Hospital, Lahore \\ ${ }^{2}$ House Officer, Services Hospital, Lahore \\ ${ }^{3}$ Assistant Professor, department of Family Medicine, University of Lahore \\ Corresponding author: Sidra Khalid, Email: farooqsidra123@gmail.com
}

\begin{abstract}
Background and Aim: A stroke, also known as a cerebrovascular accident, is defined as the sudden onset of a focal neurologic deficit caused by a disruption in blood flow to parts of the brain. The purpose of this study was to evaluate the frequency of dyslipidemia in stroke patients.

Materials and Methods: This cross-sectional study was carried out on 184 stroke patients in Medical department of Services Hospital, Lahore for duration of six months i.e from November 2020 to June 2021. All the stroke patients admitted during the study period were enrolled. Demographic details, past medical and family history, stroke risk factors, blood pressure, body mass index, and diabetic state were noted. Fasting blood samples were taken from individuals of stroke diagnosed based on CT scan. Lipid profiles including triacylglycerol, cholesterol, fasting blood glucose, low-density lipoproteins, and glycosylated hemoglobin were all measured from an individual blood samples. SPSS version 20 was used for data analysis.

Results: Of the total 184 stroke patients, $123(66.8 \%)$ were male patients while $61(33.2 \%)$ were females. The overall mean age was $41.35 \pm 12.76$ years whereas the mean body mass index was $37.61 \pm 10.91 \mathrm{Kg} / \mathrm{m} 2$. Out of 184 patients, the prevalence of prevalent risk factors such as hypertension, diabetes mellitus, and smoking was found $146(79.5 \%), 89(48.2 \%)$, and $58(31.7 \%)$ respectively. The prevalence of Hypercholesterolemia $(\mathrm{mg} / \mathrm{dl})$, Hypertriglyceridemia $(\mathrm{mg} / \mathrm{dl})$, High LDL (mg/dl) levels, high VLDL $(\mathrm{mg} / \mathrm{dl})$, and low HDL was $49(26.4 \%), 37(20.1 \%), 31(16.8 \%), 23(12.5 \%)$, and $13(7.1 \%)$ respectively. The abnormalities in $\mathrm{HbA1c}$ and fasting blood glucose were found in 93 (50.6\%) and 95 (51.4\%).

Conclusion: Dyslipidemia was more prevalent in ischemic stroke patients. The smoker and male population are more susceptible to stroke risks that involve high LDL, high HbA1c, low HDL, hypertension, and higher fast blood glucose. Family history and diabetes are other risk factors for stroke. Appropriate intrusion for alteration of uneven lipid profile can improve stroke prognosis and prevention
\end{abstract}

Keywords: Dyslipidemia; Ischemic Stroke, Cholesterol

\section{INTRODUCTION}

Stroke, also known as a cerebrovascular accident (CVA), is the second major causes of morbidity and mortality around the globe. In United State, accounting for every year, 165,000 people die due to stroke alone [1]. Stroke is caused by a disruption in the blood supply to the brain, which reduces the oxygen and nutrients supply to the brain tissues, causing damage and ischemia [3, 4]. Focal neurological deficit is another stroke risk factor which could give symptoms such as face numbness, and weakness in arm and leg [5]. Vision difficulty, confusion, loss of balance or coordination, fainting or unconsciousness, difficulty walking, difficulty speaking or understanding speech, dizziness, and severe headache with an unknown cause are other symptoms. Controllable risk factors include tobacco use, obesity, high blood pressure, sedentary lifestyle, atrial flutter, diabetes, hyperlipidemia, and atherosclerosis. Uncontrollable risk factors for stroke, on the other hand, include age, family history, gender, and stroke history [6].

Elevated cholesterol levels and dyslipidemia are menace for a variety of diseases such as hypertension, stroke, and peripheral vascular disease [7], which can be defined as lipoprotein metabolism disorders, such as lipoprotein paucity or exceeding production $[8,9]$. Ischemic stroke risk increases with elevated LDL levels whereas greater risk is associated with lower HDL [10]. Few epidemiological investigation have produced contradictory results about the relationship of ischemic stroke with dyslipidemia while increased levels of LDL may enhance the hemorrhagic stroke risk $[11,12]$. Computed tomography is the prior choice of research whereas ischemic stroke with suitable brain stem region through Magnetic resonance imaging. Due to the regeneration of brain tissue, the incidence is significantly irreversible. Therefore, earlier diagnosis is mandatory. Dyslipidemia association is different than ischemic stroke results. Hypertension and hypercholesterolemia significantly contribute to stroke whereas carbohydrates and polyunsaturated fat are associated with an increased risk of stroke [13]. The stroke risk can be mitigated with adequate nutrition, stress management, exercise, and lack of control over oral infection [14]. Lower levels of low-density lipoprotein and higher levels of high-density lipoprotein are linked to a lower risk of stroke. Despite screening guidelines and evidence of statin efficacy, there are numerous barriers to maintaining adequate lipid control [15]. As a result, assessing dyslipidemia is critical. The current study aimed to assess the incidence of dyslipidemia in ischemic stroke patients.

\section{MATERIAL AND METHODS}

This cross-sectional study was carried out on 184 stroke patients in Medical department of Services Hospital, Lahore for duration of six months i.e from November 2020 to June 2021. All the stroke patients admitted during the study period were enrolled. Demographic details, past medical and family history, stroke risk factors, blood pressure, body mass index, and diabetic state were noted. Fasting blood samples were taken from individuals of stroke diagnosed based on CT scan. Lipid profiles including triacylglycerol, cholesterol, fasting blood glucose, low-density lipoproteins, and glycosylated hemoglobin were all measured from an individual blood samples. Prior to study conduction, ethical approval was taken from the institutional ethical committee. Informed consent in written form was obtained from each individual. All the patients with brain tumors, trauma, and refused to consent forms were excluded. Patients of either gender with an age range from 20 years to 80 years were enrolled. The demographic details such as age, gender, and social status, ischemic heart disease, stroke previous history, diabetes, family history, and atrial fibrillation were taken and recorded. Fasting blood samples were investigated for lipid profile, serum homocysteine, and blood sugar levels.

Fasting venous blood samples were taken from stroke patients in order to determine cholesterol, HDL, LDL, FBG, TAG, and $\mathrm{HbA} 1 \mathrm{c}$. Hyperlipidemia was referred to cholesterol of $200 \mathrm{mg} / \mathrm{dl}$ or higher, TAG of $200 \mathrm{mg} / \mathrm{dl}$ or higher, LDL of $130 \mathrm{mg} / \mathrm{dl}$ or higher, and $\mathrm{HDL}$ of $<40 \mathrm{mg} / \mathrm{dl}$ or higher in men and less than $50 \mathrm{mg} / \mathrm{dl}$ in women [16]. Normoglycemic patients with diabetes history who were taking oral hypoglycemic or insulin were referred to diabetics. Individual who smoked one cigarette per day for 3 months was 
considered smoker while an individual with body mass index above $30 \mathrm{~kg} / \mathrm{m} 2$ were considered obese. SPSS version 20 was used for data analysis.

\section{RESULTS}

Of the total 184 stroke patients, $123(66.8 \%)$ were male patients while $61(33.2 \%)$ were females. The overall mean age was $41.35 \pm 12.76$ years whereas the mean body mass index was $37.61 \pm 10.91 \mathrm{Kg} / \mathrm{m} 2$. Out of 184 patients, the prevalence of prevalent risk factors such as hypertension, diabetes mellitus, and smoking was found $146(79.5 \%), 89(48.2 \%)$, and $58(31.7 \%)$ respectively as shown in as shown in Figure-1. The prevalence of Hypercholesterolemia (mg/dl), Hypertriglyceridemia ( $\mathrm{mg} / \mathrm{dl})$, High LDL $(\mathrm{mg} / \mathrm{dl})$ levels, high VLDL (mg/dl), and low $\mathrm{HDL}$ was 49 $(26.4 \%), 37(20.1 \%), 31(16.8 \%), 23(12.5 \%)$, and $13(7.1 \%)$ respectively as shown in Table-1. The abnormalities in $\mathrm{HbA} 1 \mathrm{c}$ and fasting blood glucose were found in $93(50.6 \%)$ and 95 (51.4\%). Figure-2 demonstrate the gender distribution of all the patients. The age-wise distribution of the patients was as follows; $<35$ years were $31(16.8 \%), 116(63 \%)$ were in between 35 years and 60 years, and37 (20.2\%) were above 60 years as shown in Figure-3.

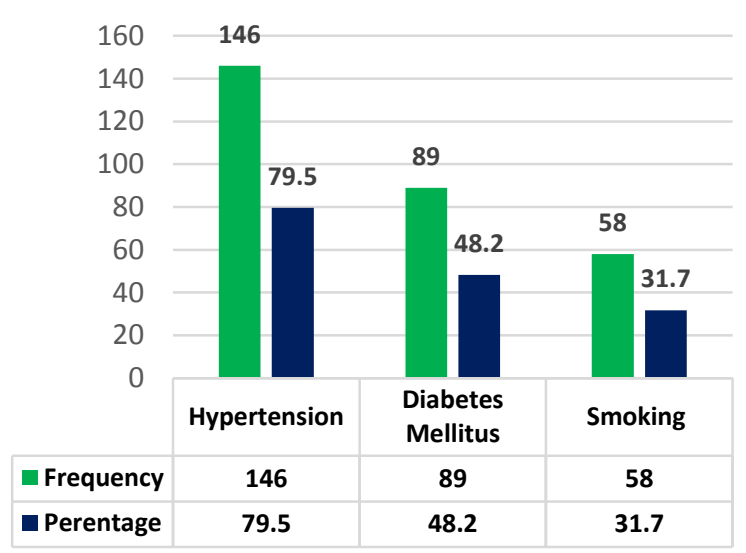

Frequency Perentage

Figure-1 Prevalence of prevalent risk factors $(n=184)$

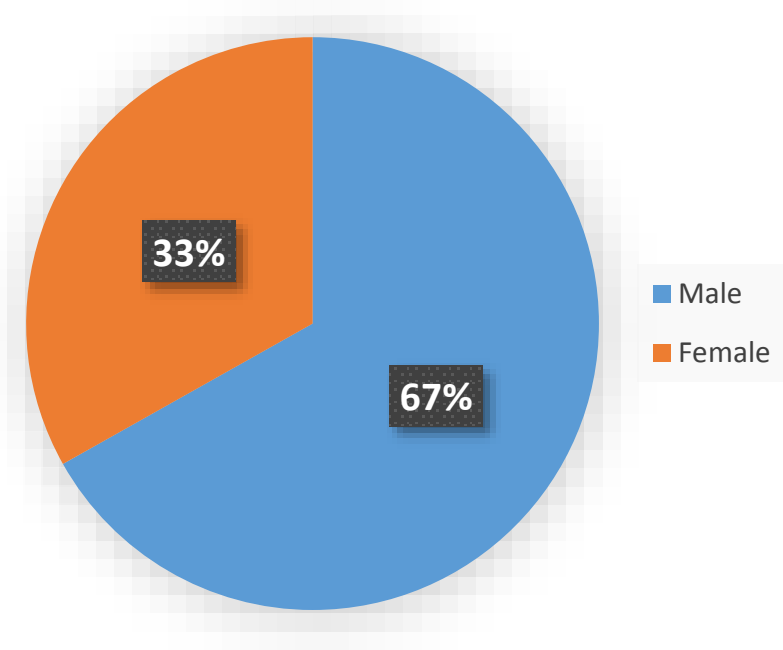

Figure-2 Gender distribution ( $n=184)$

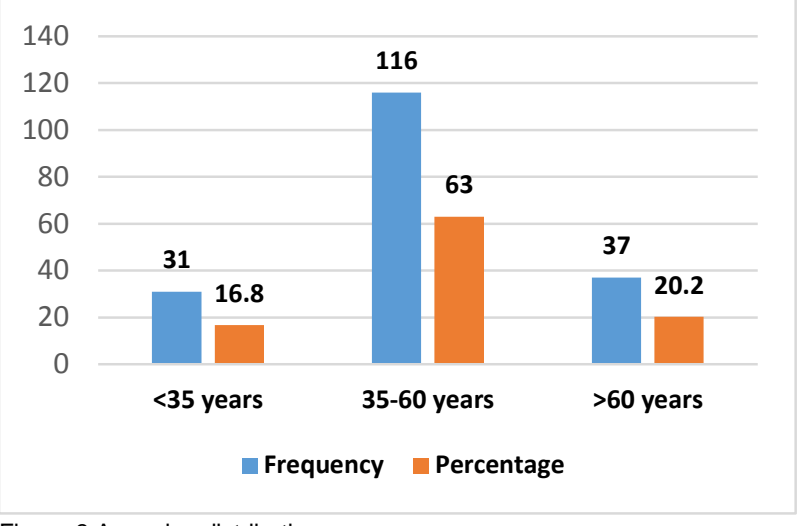

Figure-3 Age-wise distribution

Tabe-1. Ischemic stroke and lipid profile associations

\begin{tabular}{|l|l|l|l|}
\hline Profile & Mean & Frequency $\mathrm{n}$ & Percentage \\
\hline $\begin{array}{l}\text { Hypercholesterolemia } \\
(>200 \mathrm{mg} / \mathrm{dl})\end{array}$ & $151.7 \pm 13.8$ & 49 & 26.2 \\
\hline $\begin{array}{l}\text { Hypertriglyceridemia } \\
(>150 \mathrm{mg} / \mathrm{dl})\end{array}$ & $203.2 \pm 29.6$ & 37 & 20.1 \\
\hline $\begin{array}{l}\text { High LDL }(>130 \\
\mathrm{mg} / \mathrm{dl}) \text { levels }\end{array}$ & $139.9 \pm 32.4$ & 31 & 16.8 \\
\hline $\begin{array}{l}\text { High VLDL }(<35 \\
\mathrm{mg} / \mathrm{dl})\end{array}$ & $29.5 \pm 4.62$ & 23 & 12.5 \\
\hline Low HDL & $41.3+14.24$ & 13 & 7.1 \\
\hline
\end{tabular}

\section{DISCUSSION}

Stroke is considered a major health issue and ranked among four reasons for worldwide mortality. Other major risk factors are dyslipidemia involving high-density lipoproteins for stroke, atherosclerosis, coronary heart disease, thrombosis, and cerebrovascular disease. In our study, it has been reported that male populations are more susceptible to stroke as compared to females. Which resembles the Reynolds et al [17] findings that male suffered more from stroke with a ratio of 1.7:1 in the ischemic stroke group. Stroke presentation varies from restrained to severe, depending on the nature of attack and brain involved area [18]. Dyslipidemia's role in stroke pathogenesis is less clear. Various studies reported conflicting findings of stroke and dyslipidemia association [19]. Dyslipidemia is the prime risk factor for ischemic stroke which leads to decreased concentration of HDL-C and increased LDL-C and plasma triglyceride levels, as a substantial risk contributor for stroke and peripheral vascular diseases [20, 21]. Serum HDL-c has antiatherogenic properties that allow flow of cholesterol to liver from peripheral cells, providing a defensive outcome [22].

Poupore et al. discovered elevated LDL and higher lipoprotein levels in ischemic stroke patients compared to dyslipidemia trends in ischemic stroke patients [23]. They found that hypertension (74.3\%), hyperglycemia (64\%), and dyslipidemia $(57.1 \%)$, were the common risk factors and their findings on dyslipidemia were similar to ours. Furthermore, they found that the prevalence of dyslipidemia in men and women was $68.4 \%$ and $43.7 \%$ respectively. Also, dyslipidemia was found common in elder age patients>65 (63.2\%) which was more prevalent compared to the general population (53.7\%). The prevalence of male and female was $79 \%$ and $21 \%$ respectively as reported by local study. Stroke patients had hypertension (65\%), diabetes mellitus (36.3\%), dyslipidemia (32.7\%), and smoking [24].

Despite the fact that human diseases had numerous potential causes. Family history is the most prevalent risk factors for diseases such as diabetes, stroke, and cancer. An HTN and diabetes family history was found to be associated with an increased risk of stroke. The main cerebrovascular risk factor in stroke was found to be a family history of HTN $(81 \%)$, and other history such as stroke (50\%) and DM (58\%) [25]. the role of 
hypertension, cigarette smoking, diabetes, and other risk factors in stroke development is well established [26]. The most common risk factor for stroke $(79.5 \%)$ was discovered to be hypertension, followed by smoking (31.7\%) and diabetes (48.2\%). Furthermore, the hypertension high prevalence raises the risk of stroke. The stroke patient's lipid profile was examined, and it was discovered that patients had cholesterol levels of $200 \mathrm{mg} / \mathrm{dl}$, and the mean total cholesterol was $163.1 \mathrm{mg} / \mathrm{dl}$, which was consistent with other findings that showed insignificant association between stroke risk and cholesterol level [27]. Other research [28, 29] found that stroke patients had increased cholesterol levels indicating another risk factor for stroke. These findings could imply that the association between high level of TAG and stroke risk is still unclear, which is consistent with previous research that found no link between higher TAG levels and stroke risk [30].

\section{CONCLUSION}

Dyslipidemia was more prevalent in ischemic stroke patients. The smoker and male population are more susceptible to stroke risks that involve high LDL, high $\mathrm{HbA1c}$, low HDL, hypertension, and higher fast blood glucose. Family history and diabetes are other risk factors for stroke. Appropriate intrusion for alteration of uneven lipid profile can improve stroke prognosis and prevention.

\section{REFERENCES}

1. Brechtel L, Poupore N, Stoikov T, Roley LT, Emerson JF, Nathaniel $\mathrm{T}$. Comorbidities associated with different levels of total cholesterol in male and female acute ischemic stroke patients. Medicine (Baltim) 2020;99(52):e23870.

\subsection{7/MD.0000000000023870.}

https://doi.org/

2. Simundic AM, Nikolac N, Topic E, Basic-Kes V, Demarin V. Are serum lipids measured on stroke admission prognostic? Clin Chem Lab Med 2018;46(8):1163-7. https://doi.org/10.1515/cclm.2018.233. [6] Beltowski J. Reverse epidemiology in ischemic stroke: high cholesterol as a predictor of improved survival in stroke patients. Clin Lipidol 2017;9(2):135-9. https://doi.org/10.2217/clp.14.2.

3. Kogiso T, Hashimoto E. Are low triglyceride levels the cause or an outcome of advanced liver fibrosis in elderly patients with nonalcoholic fatty liver disease? J Gastroenterol Hepatol 2020;35(9):1459-60. https://doi.org/10.1111/jgh.15226.

4. Rost NS, Bottle A, Lee JM, Randall M, Middleton S, Shaw L, et al. Stroke severity is a crucial predictor of outcome: an international prospective validation study. J Am Heart Assoc. 2016;5(1). https://doi.org/10.1161/jaha.115.002433.

5. Lu D, Li P, Zhou Y, Xu X, Zhang H, Liu L, et al. Association between serum non-highdensity lipoprotein cholesterol and cognitive impairment in patients with acute ischemic stroke. BMC Neurol 2016;16(1):154. https://doi.org/10.1186/s12883- 016-0668-2.

6. Cheng KH, Lin JR, Anderson CS, Lai WT, Lee TH, SRICHS Group. Lipid paradox in statin-naïve acute ischemic stroke but not hemorrhagic stroke. Front Neurol 2018;9: 541. https://doi.org/10.3389/fneur.2018.00541.

7. Blum B, Wormack L, Holtel M, Penwell A, Lari S, Walker B, et al. Gender and thrombolysis therapy in stroke patients with incidence of dyslipidemia. BMC Wom Health 2019;19(1):11. https://doi.org/10.1186/s12905-018-0698-6.

8. Nathaniel TI, Ubah C, Wormack L, Gainey J. The telestroke and thrombolysis therapy in diabetic stroke patients. Diabetol Metab Syndrome 2019;11. https:// doi.org/10.1186/s13098-019-0421-2.

9. Fleming T, Blum B, Averkamp B, Sullivan J, Nathaniel T. Effect of antihypertensive medications on thrombolysis therapy and outcomes in acute ischemic stroke patients. J Clin Hypertens 2019;21(2):271-9. https://doi.org/10.1111/jch.13472.

10. Fredwall M, Sternberg S, Blackhurst D, Lee A, Leacock R, Nathaniel TI. Gender differences in exclusion criteria for recombinant tissuetype plasminogen activator. J Stroke Cerebrovasc Dis : Offc. J. Nat Stroke. Assoc. 2016;25(11):2569-74. https://doi.org/10.1016/j.jstrokecerebrovasdis.2016.06.012.

11. Nathaniel TI, Cochran T, Chaves J, Fulmer E, Sosa C, Yi S, et al. Comorbid conditions in use of recombinant tissue plasminogen activator (rt-PA) for the treatment of acute ischaemic stroke. Brain Inj 2016;30(10):1261-5. doi.org/10.1080/02699052.2016.1186840.
12. Oluyemi RR, Ajani IF, Penwell A, Lari S, Walker B, Nathaniel IT. In acute ischemic stroke patients with a history of smoking; are more women than men more likely to be excluded from thrombolysis therapy? Women Health 2020;16:1-12.

13. Sanders KA, Patel R, Kiely JM, Gwynn MW, Johnston LH. Improving telestroke treatment times in an expanding network of hospitals. J Stroke Cerebrovasc Dis 2016;25(2):288-91. https://doi.org/10.1016/j.jstrokecerebrovasdis.2015.09.030.

14. Nguyen-Huynh MN, Klingman JG, Avins AL, Rao VA, Eaton A Bhopale S, et al. Novel telestroke program improves thrombolysis for acute stroke across 21 hospitals of an integrated healthcare system. Stroke 2018;49(1):133.

doi.org/10.1161/strokeaha.117.018413.

15. Fazzone B, Morris G, Black LA, Williams JA, Leacock R, Sternberg S, et al. Exclusion and Inclusion Criteria for Thrombolytic Therapy in an Ischemic Stroke Population.e 4(2): 1112. J. Neurol. Disord. Strok 2016;4(2):1-5.

16. Lawson TR, Brown IE, Westerkam DL, Blackhurst DW, Sternberg S, Leacock $R$, et al. Tissue plasminogen activator (rt-PA) in acute ischemic stroke: outcomes associated with ambulation. Restor Neurol Neurosci 2015;33:301-8. https://doi.org/10.3233/ RNN-140480.

17. Reynolds M, Blum B, Brechtel L, Gainey G, Nathaniel IT. Clinical risk factors associated with functional outcomes of thrombolytic therapy in stroke and nonstroke units. J Exp Stroke Trans Med. 2017;1:22-8.

18. Blum B, Brechtel L, Nathaniel T. Thrombolysis therapy in specialized and nonspecialized stroke units. Arch Med Res 2018;49(8):588-97. https://doi.org/ 10.1016/j.arcmed.2019.01.002

19. Aboa-Eboule C, Binquet C, Jacquin A, Hervieu M, Bonithon-Kopp C, Durier J, et al. Effect of previous statin therapy on severity and outcome in ischemic stroke patients: a population-based study. J Neurol 2013;260(1):30-7. https://doi.org/ 10.1007/s00415-012-65809.

20. Heldner MR, Mattle HP, Jung S, Fischer U, Gralla J, Zubler C, et al. Thrombolysis in patients with prior stroke within the last 3 months.

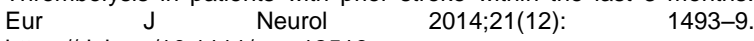
https://doi.org/10.1111/ene.12519.

21. Wouters A, Nysten C, Thijs V, Lemmens R. Prediction of Outcome in Patients with acute ischemic stroke Based on initial severity and improvement in the First 24 h. Front Neurol 2018;9. https://doi.org/10.3389/fneur.2018.00308.

22. Heldner MR, Zubler C, Mattle HP, Schroth G, Weck A, Mono ML, et al. National Institutes of health stroke scale score and vessel occlusion in 2152 patients with acute ischemic stroke. Stroke 2013;44(4):1153. https://doi.org/10.1161/ strokeaha.111.000604.

23. Poupore N, Strat D, Mackey T, Brown K, Snell A, Nathaniel IT. Thrombolytic therapy in Ischemic Stroke Patients with a preceding transient ischemic attack (TIA) in a telestroke and non-telestroke setting. Neurol Clinc Neurosci. 2020;8(5): 298-308. https://doi.org/10.1111/ncn3.12426.

24. Schneck MJ. Current stroke scales may Be partly responsible for worse outcomes in posterior circulation stroke. Stroke 2018;49(11):2565-6. https://doi.org/10.1161/ STROKEAHA.118.023201.

25. Gainey J, Blum B, Bowie B, Cooley K, Madeline L, Ervin EL, et al. Stroke and dyslipidemia: clinical risk factors in the telestroke versus non-telestroke. Lipids Health Dis 2018;17(1):226. https://doi.org/10.1186/s12944-018-0870-x.

26. Thomas IN, Gainey J, Wormack J, Brechtel L. Functional outcome model for a telestroke-guided tissue plasminogen activator treatment of stroke. Int Stroke Conf Proc. 2018;Suppl 1:45.

27. Lawson TR, Brown IE, Westerkam DL, Blackhurst DW, Sternberg S Leacock $R$, et al. Tissue plasminogen activator (rt-PA) in acute ischemic stroke: outcomes associated with ambulation. Restor Neurol Neurosci 2015;33(3):301-8. https://doi.org/ 10.3233/rnn-140480.

28. Wozniak MA, Kittner SJ, Tuhrim S, Cole JW, Stern B, Dobbins M, et al. Frequency of fabry disease among young caucasian and africanAmerican men with first ischemic stroke. Stroke 2009;40(4). E184E184.

29. Bhatia R, Sharma G, Garg A, Roy A, Patel C, Sreenivas V, et al. Prevalence of symptomatic and asymptomatic coronary artery disease in patients with stroke and transient ischemic attack. Int $\mathrm{J}$ Stroke 2018;13. 37-37

30. Brechtel L, Poupore N, Monroe M, Knisley K, Sanders C, Edrissi C, Rathfoot C, Nathaniel TI. Role of dyslipidemia in ischemic stroke patients treated in the telestroke network. Advances in Medical Sciences. 2021 Sep 1;66(2):254-61 